\title{
A PRODUÇÃo CIENTíFICA dA ENFERMAGEM NO CONTEXTO DA FAMÍLIA DA CRIANÇA COM DEFICIÊNCIA
}

Maria Angélica Marcheti - Enfermeira Doutora em Ciências - Professora Associada da Universidade Federal do Mato Grosso do Sul UFMS e Líder do Laboratório de Estudos e Pesquisas em Intervenção Familiar - LEPIF, e-mail: mamarcheti@gmail.com

A área de enfermagem da família ainda se encontra em fase de formação de um corpo de conhecimento teórico para sustentar sua prática. Nesse sentido, os enfermeiros são desafiados a realizar pesquisas que produzam as melhores evidências para o cuidado da família em situações de adoecimento de um de seus membros. A transferência do conhecimento teórico produzido torna-se fundamental para promover mudanças na prática dos profissionais com a família.

Quando se trata de famílias que vivem o contexto da deficiência na criança, os desafios são ainda mais impactantes influenciando o bem-estar de toda a família. Em uma revisão da literatura sobre a experiência da família com uma criança com deficiência, os autores agruparam os achados em cinco eixos temáticos: 0 Diagnóstico de Deficiência e a sua Repercussão na Família, cujos estudos evidenciam o impacto emocional do nascimento de uma criança com deficiência sobre a família, as alterações na dinâmica familiar e em seu mundo de relacionamentos; A Convivência Familiar com a Criança e o Adolescente, destacando estudos que dizem respeito à sobrecarga imposta pela deficiência na unidade familiar, os arranjos da família para manejar a situação, a redefinição de papéis e as prioridades da família; Desafios da Família da Criança e do Adolescente com Deficiência, estudos que dão ênfase às necessidades de informação e de redes de suporte social, assim como a necessidade de incremento de políticas públicas que garantam à família o acesso aos recursos tecnológicos para a manutenção da saúde, do crescimento e desenvolvimento da criança; Forças da Família no Contexto da Deficiência, trazendo estudos que discorrem sobre a adaptação positiva e a força familiar para o enfrentamento da situação de deficiência, com a perspectiva de que essa situação traga contribuições positivas para a vida e o bem-estar de toda a família; A Família em Relação ao Cuidado Prestado pela Equipe de Saúde, evidenciando o modo como a família percebe a abordagem do profissional de saúde e o despreparo da equipe para a abordagem à família(1).

Apesar dos avanços no conhecimento sobre a experiência e o funcionamento familiar no contexto da deficiência e do movimento de pesquisadores interessados nessa temática, observa-se que ainda há uma lacuna em relação a estudos de intervenção, imprescindíveis para promover o cuidado da família, ajudá-la no enfrentamento da experiência e no manejo das interações familiares, e subsidiar a formulação de políticas públicas que atendam às necessidades e demandas dessa população. 
Um estudo de reflexão destaca que pesquisa de família é aquela compreendida e operacionalizada para possibilitar a compreensão da unidade familiar. As autoras remetem a dois importantes desafios que se apresentam ao pesquisador e em particular na área de enfermagem da família, a saber: aprimorar a qualidade da pesquisa sobre família, e tornar as evidências da pesquisa sobre famílias relevantes ao público que a consome(2).

Nós enfermeiros também precisamos nos dedicar a produzir instrumentos de medida de fenômenos subjetivos que envolvam a família como unidade de cuidado, tais como a medida de estresse da família, de ansiedade, de vulnerabilidade, entre outros. Os estudos com foco na família são oriundos, em sua maioria, de pesquisas qualitativas, com fundamentação teórico-filosóficas que consideram o humano e as interações. No entanto é preciso avançar na geração de estudos clínicos randomizados que produzam evidências com força de recomendação.

As propostas de intervenções com família ainda carecem de estudos de avaliação de sua eficácia. Nesse sentido, é preciso identificar novos construtos a serem medidos, desenvolver habilidades em avaliar a qualidade de instrumentos de medida, identificar elementos comuns que possam ser compartilhados em programas de prática ou pesquisa, explorar novas abordagens para compreender as famílias e incorporar variáveis familiares no sistema de documentação.

Pensar o rumo que queremos dar para as nossas pesquisas e avançar nos aspectos abordados, e na expansão dos programas já existentes de avaliação e intervenção com famílias em seu contexto social e político, assegurará novos dados sobre intervenções eficazes, garantindo o avanço da prática profissional, de políticas voltadas ao cuidado da família e da ciência da enfermagem da família.

\section{REFERENCIAS}

1. Marcheti MA, Mandetta MA. Criança e adolescente com deficiência: programa de intervenção de enfermagem com família. Goiânia: AB; 2016. Disponível em: file:///C:/Users/Michelly/Downloads/2510369792-1-PB.pdf

2. Ângelo $M$, Bousso RS, Rossato $L M$, Damião $E B C$, Silveira $A O$, Castilho $A M C M$. et al. Família como categoria de análise e campo de investigação em enfermagem. Rev Esc Enferm USP [Internet]. 2009 [citado

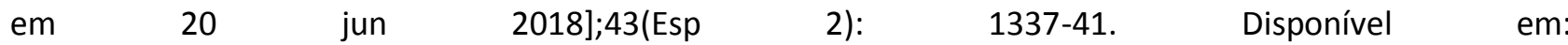
http://www.scielo.br/pdf/reeusp/v43nspe2/a33v43s2.pdf

Como citar este artigo:

Marcheti MA. A Produção Científica da Enfermagem no Contexto da Família da Criança com Deficiência. 2018;8:eEditorial. [Access ]; Available in: .DOI: http://dx.doi.org/10.19175/recom.v8i0.3001 